\title{
Avaliação da oferta de ensino fundamental pela rede pública e sua distribuiç̣̃o espacial: aplicaç̃̃o ao municipio de Niterói (RJ)
}

\section{Nelio D. Pizzolato}

Guilherme Gomes

da Silva

Satie Mizubuti

Palavras-chave: localização de

escolas; rede escolar; ensino

básico; capacidade da rede.

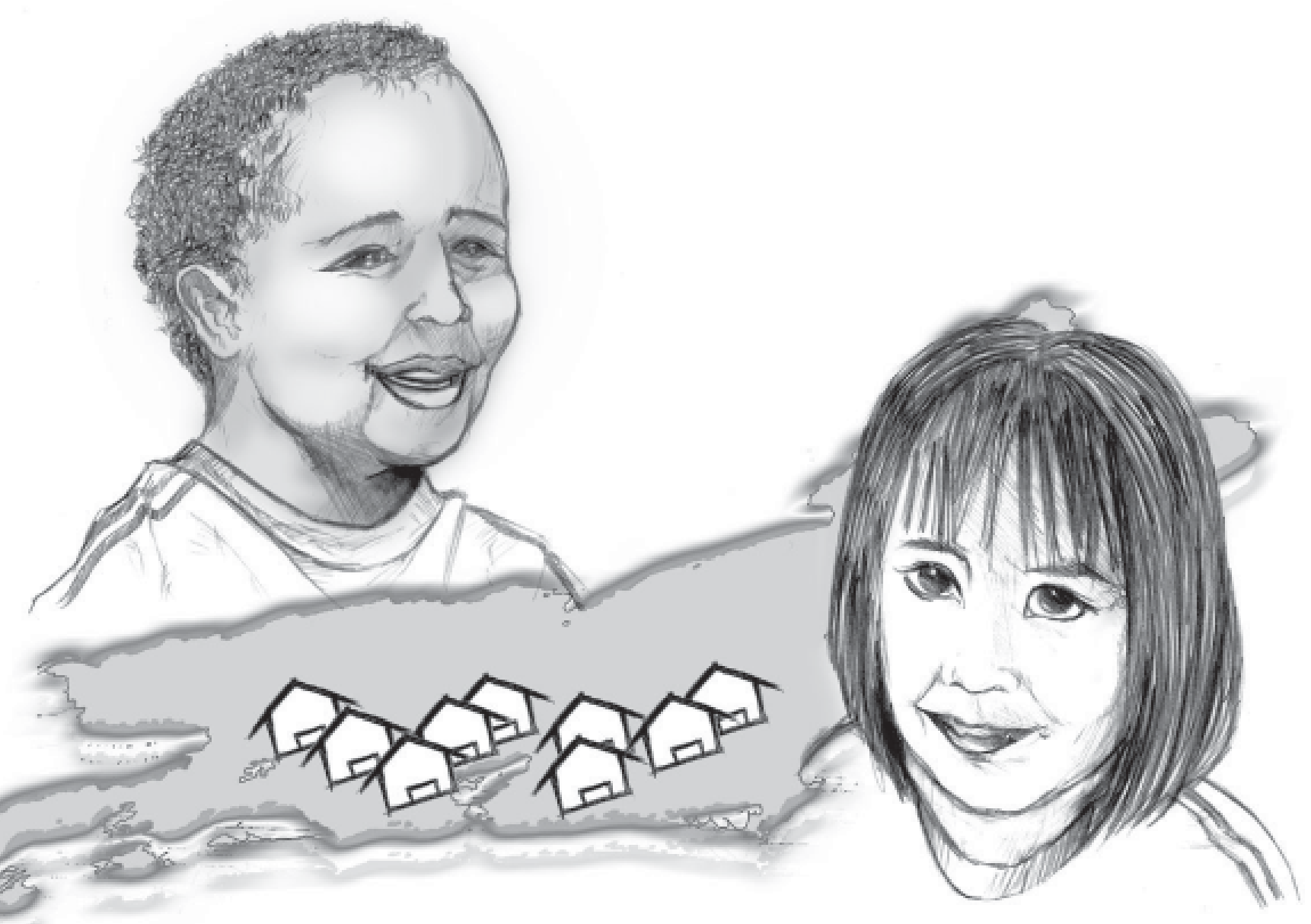




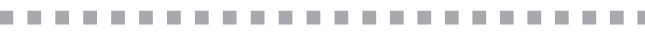<smiles>[AlH2]</smiles>

isa a dois objetivos, ambos ilustrados com dados escolares do município de Niterói (RJ). O primeiro consiste em uma proposta metodológica para avaliar a oferta de vagas no ensino fundamental de forma a manter escolarizados todos os jovens na faixa de 7 a 14 anos. O segundo consiste em avaliar a distribuição espacial das escolas da rede pública, identificando regiões com excesso e/ou escassez de vagas. O caso estudado apresentou a surpresa de encontrar uma população escolar bastante superior à população demográfica, sugerindo a migração de alunos de outros municípios. Quanto à distribuição espacial das escolas, o estudo apontou as poucas áreas em que haveria necessidade adicional de vagas, mas destacou que, nos bairros onde predomina a população de classe média, poderá haver forte escassez, se tais segmentos optarem pela escola pública.

\section{Introdução}

Prioridade absoluta à educação constitui-se uma das raras unanimidades nacionais. Existe o consenso que a eventual inserção do País no bloco dos países do
Primeiro Mundo tem como precondição a elevação dos níveis culturais da população, o que impõe o cumprimento pleno da missão educacional da escola. Para o País atingir tal meta ambiciosa, são necessários investimentos maciços em todos os níveis de educação, especialmente o básico, incluindo qualificação do corpo docente, ampliação dos anos de escolaridade, aumento da jornada escolar, modernização dos equipamentos escolares, manutenção sistemática da rede, melhoria da qualidade do ensino, etc.

Não se pode negar diversos indicadores favoráveis, tal como a notável ampliação das taxas de escolarização entre os anos de 1991 e 1996 (Brasil, 1997). A melhoria desses indicadores em escala nacional foi, certamente, favorecida pela crescente conscientização do problema, assim como pela introdução de diversos programas para a ativação do fluxo escolar, de modo a reduzir a distorção série/idade e abrir espaço para os ingressantes, tais como os programas de aceleração da aprendizagem, o regime da progressão continuada, a supressão das classes de alfabetização, etc.

Entretanto, o processo cultural, conseqüente à qualidade do ensino, é complexo, e da retórica à prática surgem enormes dificuldades. Por um lado, os setores mais afluentes da sociedade encontram na escola privada a satisfação de suas demandas e não se propõem induzir o aperfeiçoamento da ação do poder público. Por outro lado, para a escola pública, que atende a uma sociedade heterogênea, a missão educacional é extremamente complexa, diante dos multifacetados problemas socioculturais, pois dela não se espera somente a alfabetização, mas, igualmente, socialização, formação cívica, iniciação profissional, etc. Embora muitos governantes, movidos por princípios de afirmação social e espírito de modernidade, estabeleçam exemplos de radical priorização da educação, muitos outros, em face da escassez de recursos, da ausência de frutos no curto prazo e da falta de pressões no plano político, tendem a marginalizar a educação e relativizar a presumida prioridade.

Dentre os objetos de questionamento mais freqüente da rede pública de ensino estão a insuficiência de vagas, hoje menos crítica do que em passado recente, e também a sua distribuição espacial, que 
privilegiaria certas áreas em detrimento de outras mais carentes. Normalmente, ambos os questionamentos são inspirados em situações concretas, mas pontuais. Quanto ao problema de mais simples abordagem, qual seja, a quantificação da população fora da escola, sua correta estimativa, nas áreas urbanas, costuma ser uma questão controversa. Vários fatores dificultam tal determinação, tais como: a mobilidade demográfica, a explosão populacional em áreas favelizadas; a demanda reprimida por diversos fatores como a ignorância, a pobreza, a repetência, etc.

Quanto ao problema mais complexo de avaliar a distribuição espacial da rede pública, aí, então, as críticas veiculadas são notoriamente circunstanciais, assim como, pela inerente complexidade do problema, nunca se aventuraram a identificar a localização ideal. A rede pública, na prática, é produto de um desenvolvimento histórico que responde espasmodicamente ao crescimento populacional. Diante da inexistência de metodologias técnicas para localizar novas construções escolares ou expandir as existentes, as expansões observadas na rede são, sobretudo, resultados de pressões localizadas ou de decisões fortuitas, que se traduzem por eventuais equívocos, responsáveis pelas críticas subsistentes. Por outro lado, a rede particular busca atender a nichos específicos de demanda, tem um planejamento anárquico, dependente de motivações e limitações singulares e tende a ser composta por um grande número de pequenas instituições.

Com relação específica ao Estado do Rio de Janeiro, em moldes de recenseamento, o último levantamento detalhado da situação educacional foi feito pelo Censo Escolar da Região Metropolitana do Rio de Janeiro de 1977, examinado adiante. Esse Censo radiografou inúmeros dados de escolarização, deficiência, analfabetismo, desistência, modos de locomoção, tempos de deslocamento, etc., que oferecem uma perspectiva do quadro existente na época. Entretanto, o elevado crescimento populacional das áreas urbanas, particularmente agudo durante as décadas de 70 e 80, em conseqüência da intensa migração interna e do processo de urbanização, desatualizou rapidamente seus resultados.
O presente trabalho propõe modos alternativos de avaliar os dois citados problemas: capacidade e distribuição espacial da rede pública, e ilustra sua utilização no contexto do município de Niterói, Estado do Rio de Janeiro. No caso da avaliação da capacidade, o estudo sugere uma metodologia para avaliar a oferta de vagas públicas. A metodologia proposta parte do princípio de que toda população na faixa de 7 a 14 anos deve estar em uma escola, cursando o ensino fundamental. Através dos dados censitários do Instituto Brasileiro de Geografia e Estatística (IBGE), é identificada a população existente e, por outro lado, o levantamento da população escolar é obtido com apoio dos censos escolares do Instituto Nacional de Estudos e Pesquisas Educacionais (Inep) e das Secretarias Estadual e Municipal de Educação. O confronto dos dois dados permite medir a eventual escassez de vagas.

No caso da avaliação espacial, é aplicada uma metodologia já testada em diversos municípios da Baixada Fluminense, que supõe que o aluno prefira a escola mais próxima de sua residência. Basicamente, o trabalho exige o seguinte: mapas com indicação dos setores censitários; população escolarizável de cada setor, conforme apuração do IBGE; localização das escolas públicas existentes; e dados de matrícula em cada escola.

$\mathrm{Na}$ seqüência, a próxima seção examina a questão da capacidade da rede de ensino de Niterói e, diante da surpresa em frente de alguns resultados, também aplica a metodologia a dois municípios vizinhos: São Gonçalo e Itaboraí. Em seguida, vêm duas seções: uma reproduz alguns resultados relevantes do Censo Escolar de 1977 e outra apresenta o modelo de avaliação da distribuição espacial das escolas e examina sua aplicação ao município de Niterói. A última seção apresenta as conclusões.

\section{Avaliação da capacidade da rede escolar}

Avaliar a capacidade de rede escolar consiste em comparar a demanda com a oferta. $\mathrm{Na}$ expressão a seguir, entende-se que o Ensino Fundamental (EF), abrangendo da $1^{a}$ à $8^{a}$ série, deve ser idealmente realizado entre os 7 e os 14 anos. O EF pode 
ser precedido tanto pela Classe de Alfabetização (CA), de existência desejável mas não obrigatória, como pelo Pré-Escolar $(P E)$, onde se inicia o processo de integração à escola. A meta de escolarização é um porcentual que exclui a parcela da população que não freqüenta a escola regular devido a fatores diversos, tais como a freqüência a escolas especiais, a impossibilidade de estudar, o desejo de simplesmente não estudar, etc. A expressão abaixo compara demanda com oferta, supondo que o compromisso público seja a garantia de vagas no EF àqueles na faixa de 7 a 14 anos.

Demanda $=$ População escolar na faixa de 7 a 14 anos

(-) Meta de não-escolarização

Oferta $=$ Matrículas totais no EF

(-) Matrículas no EF com $<7$ anos

(-) Matrículas no EF com $>14$ anos

(-) Concluintes do EF com $<15$ anos

(+) Matrículas na CAe noPE com $>6$ anos

A expressão acima é importante para o planejamento escolar, tendo um caráter normativo. Ela parte da descrição atual do sistema, que constrange a oferta pela ineficiência série/idade, refletida no numeroso contingente acima de 15 anos ainda no sistema, embora aliviada pela ausência dos acima de 6, demandantes, entretanto, de outros recursos dos sistemas de ensino, e também pelos concluintes precoces, abaixo dos 15 anos, que deixaram o sistema por conclusão do ciclo de estudos. A expressão será avaliada com os dados referentes a Niterói, e também ampliada aos municípios de São Gonçalo e Itaboraí.

\section{Avaliação do caso de Niterói}

Os dados de população de Niterói, por faixa etária, estão na Tabela 1, ficando o Censo de 1991 na linha superior e o Censo de 1996, na coluna inferior. Embora a população total tenha aumentado $3,25 \%$, nota-se sobre as primeiras faixas etárias os efeitos da redução da taxa de natalidade, o que reduzirá, mais adiante, a demanda por vagas nos sistemas de ensino. Associando-se o ensino fundamental à faixa etária de 7 a 14 anos, a demanda escolar em 1996 seria constituída por 3/5 da população na faixa de 5 a 9 anos e por todos aqueles na faixa de 10 a 14 anos, ou seja:

$3 / 5 \times 32.099+36.025=55.284$ alunos

Tabela 1 - População residente por grupos de idade - Niterói (RJ) Censos 1991 e 1996

\begin{tabular}{|c|c|c|c|c|c|c|c|c|c|}
\hline \multirow{2}{*}{$\begin{array}{l}\text { População } \\
\text { Total }\end{array}$} & \multicolumn{9}{|c|}{ Faixa etária em anos } \\
\hline & 0 a 4 & 5 a 9 & $10-14$ & $15-19$ & $20-24$ & 25-29 & $30-34$ & $35-39$ & $>40$ \\
\hline $\begin{array}{l}436.155 \\
(\mathrm{em} \mathrm{1991)}\end{array}$ & 32.558 & 35.753 & 38.598 & 36.507 & 36.798 & 39.425 & 37.582 & 35.039 & 143.896 \\
\hline $\begin{array}{l}450.364 \\
(\text { em 1996) }\end{array}$ & 30.293 & 32.099 & 36.025 & 40.436 & 37.601 & 35.436 & 38.648 & 36.939 & 162.887 \\
\hline
\end{tabular}

Fonte: IBGE.

Certamente, o valor anterior representa um limite superior da demanda para o ensino regular, pois há de aplicar um fator inferior a 1,0, denominado de meta de escolarização, de modo a excluir a parcela da população que não freqüenta a escola regular devido a fatores diversos, tais como a freqüência a escolas especiais, a impossibilidade de estudar, o desejo de simplesmente não estudar, etc. Admitindo-se para
Niterói uma meta de escolarização de $97 \%$, valor justificado adiante, tem-se:

$55.284 \times 0,97=53.626$ alunos

As Tabelas 2 e 3 indicam, respectivamente, a matrícula inicial do ensino fundamental nas três redes existentes: estadual (EE), municipal (EM) e particular (P), nos anos de 1991 e de 1996, e a 
composição etária dos estudantes das três redes, no ano de 1996.

Dois aspectos ressaltam na Tabela 2. Um deles é a presença significativa da escola particular no processo de ensino, que pode se explicar pelo mesmo Censo do IBGE que coloca Niterói como o município de maior renda per capita no Rio de
Janeiro. Entretanto, a matrícula na escola particular sofreu uma sensível redução no período coberto pela tabela. A justificativa corrente para tal decréscimo encontra-se no chamado empobrecimento da classe média que, obviamente, fica condicionado à evolução da rede pública e à melhoria de sua qualidade.

Tabela 2 - Matrícula inicial no ensino fundamental - Niterói (RJ)
Censos 1991 e 1996

\begin{tabular}{|l|c|c|c|c|c|}
\hline \multirow{2}{*}{$\begin{array}{l}\text { População } \\
\text { Total }\end{array}$} & \multicolumn{2}{|c|}{1991} & \multicolumn{2}{c|}{1996} & Evolução \% \\
\hline Estadual & Matrículas & Porcentagem & Matrículas & Porcentagem & 1996/1991 \\
\hline Municipal & 29.610 & 40,5 & 32.489 & 46,0 & 9,72 \\
\hline Particular & 9.378 & 12,8 & 13.122 & 18,6 & 39,92 \\
\hline Total & 34.090 & 46,6 & 24.961 & 35,4 & $-26,78$ \\
\hline
\end{tabular}

Fonte: SEE/RJ.

A Tabela 3 expõe um aspecto de particular importância, e sintomático dos problemas que afetam a educação pública no Brasil, qual seja, a distorção série/idade. Caso o aluno inicie o ensino fundamental na idade prevista, 7 anos, e avance normalmente, aos 14 anos ele estará no último ano e, aos 15, o terá concluído. Essa progressão fica bem evidente na clientela da rede particular, como mostra a linha $P$ da referida tabela, onde um número pequeno de alunos têm idade superior a 15 anos, enquanto que na rede pública, sobretudo na linha EE, o atraso na escola-rização é evidente.

\section{Tabela 3 - Matrícula inicial por idade e por rede no ensino fundamental Niterói (RJ) - 1996}

\begin{tabular}{|l|r|r|c|c|c|c|c|c|c|c|}
\hline Rede & $<$ & $\mathbf{7}$ & $\mathbf{8}$ & $\mathbf{9}$ & $\mathbf{1 0}$ & $\mathbf{1 1}$ & $\mathbf{1 2}$ & $\mathbf{1 3}$ & $\mathbf{1 4}$ & $>\mathbf{1 4}$ \\
\hline EE & 123 & 885 & 2.218 & 2.505 & 2.743 & 3.121 & 3.741 & 3.981 & 4.688 & 8.484 \\
\hline EM & 23 & 507 & 1.474 & 1.377 & 1.498 & 1.543 & 1.502 & 1.424 & 1.442 & 2.332 \\
\hline P & 135 & 1.529 & 2.887 & 2.849 & 2.958 & 2.933 & 3.232 & 3.494 & 3.007 & 1.937 \\
\hline Total & 281 & 2.921 & 6.579 & 6.731 & 7.199 & 7.597 & 8.475 & 8.899 & 9.137 & 12.753 \\
\hline
\end{tabular}

Fonte: SEE/RJ.

Com os dados de matriculados no ensino fundamental por idade, é possível determinar o número de alunos na faixa de 7 a 14 anos em cada uma das três redes de ensino. A Tabela 4 indica os cálculos correspondentes. 
Tabela 4 - Matrícula inicial na idade 7-14 anos no ensino fundamental Niterói (RJ) - 1996

\begin{tabular}{|l|r|r|r|r|}
\hline \multicolumn{1}{|c|}{ Matrícula 1ㅇ Grau } & \multicolumn{1}{c|}{ EE } & EM & P & Totais \\
\hline Todas as idades & 32.489 & 13.122 & 24.961 & 70.572 \\
\hline$<$ anos & $(123)$ & $(23)$ & $(135)$ & $(281)$ \\
\hline$>14$ anos & $(8.484)$ & $(2.332)$ & $(1.937)$ & $(12.753)$ \\
\hline Total 7-14 anos & 23.882 & 10.767 & 22.889 & 57.538 \\
\hline
\end{tabular}

Fonte: SEE/RJ.

A composição etária das Classes de Alfabetização (CA), aparentemente em via de extinção, assim como o Pré-Escolar $(\mathrm{PE})$, também são relevantes, pois há muitos alunos na faixa de 7 , ou mais de 7 anos, ainda matriculados nesses níveis, conforme é mostrado nas Tabelas 5 e 6 . De acordo com tais tabelas, o número total de matriculados na CA e no PE nas referidas faixas etárias é de: 4.024 e de 270 crianças, respectivamente.

Tabela 5 - Composição etária das classes de alfabetização - Niterói (RJ) - 1996

\begin{tabular}{|l|r|r|r|r|r|}
\hline \multicolumn{1}{|c|}{ Rede } & $<6$ anos & 6 anos & 7 anos & $>7$ anos & Total \\
\hline EE & 87 & 654 & 1.305 & 565 & 2.611 \\
\hline EM & 16 & 382 & 803 & 269 & 1.470 \\
\hline P & 113 & 1.155 & 928 & 154 & 2.350 \\
\hline Total & 216 & 2.191 & 3.036 & 988 & 6.431 \\
\hline
\end{tabular}

Fonte: Inep/MEC.

Tabela 6 - Composição etária do pré-escolar - Niterói (RJ) - 1996

\begin{tabular}{|l|r|r|r|r|r|}
\hline \multicolumn{1}{|c|}{ Rede } & $<$ anos & $\mathbf{6}$ anos & $\mathbf{7}$ anos & $>\mathbf{7}$ anos & Total \\
\hline EE & 2.991 & 1.013 & 235 & 11 & 4.250 \\
\hline EM & 1.835 & 511 & 2 & 1 & 2.349 \\
\hline P & 4.008 & 763 & 16 & 5 & 4.792 \\
\hline Total & 8.834 & 2.287 & 253 & 17 & 11.391 \\
\hline
\end{tabular}

Fonte: Inep/MEC.

Por outro lado, aos 14 anos, alguns alunos já completaram o ensino fundamental e iniciaram o médio, ou deram por concluída sua formação escolar. Para o ano de 1996, o número de concluintes não foi preciso, mas pela Tabela 7, nota-se que havia, na $8^{\mathrm{a}}$ série, 3 alunos com 12 anos e $438 \mathrm{com}$ 13 anos, perfazendo 441 alunos com perspectivas de conclusão precoce. Supondo-se aprovação integral, tem-se que cerca de 441 alunos estarão concluindo o ensino fundamental antes dos 14 anos. 
Tabela 7 - Matrícula inicial por série e idade, ensino fundamental Niterói (RJ) - 1996

\begin{tabular}{|c|c|c|c|c|c|c|c|c|c|c|c|}
\hline Série & Total & $<7$ & 7 & 8 & 9 & 10 & 11 & 12 & 13 & 14 & $>14$ \\
\hline $1^{\underline{a}}$ & 8.142 & 280 & 2.805 & 3.421 & 883 & 404 & 143 & 87 & 53 & 33 & 33 \\
\hline $2^{\mathrm{a}}$ & 8.407 & 1 & 116 & 3.049 & 3.049 & 1.005 & 583 & 322 & 124 & 86 & 72 \\
\hline $3^{\underline{a}}$ & 8.613 & - & - & 109 & 2.631 & 2.976 & 1.274 & 733 & 431 & 270 & 189 \\
\hline $4^{\mathrm{a}}$ & 8.948 & - & - & - & 140 & 2.528 & 3.025 & 1.298 & 942 & 542 & 473 \\
\hline $5^{\mathrm{a}}$ & 10.577 & - & - & - & 28 & 244 & 2.386 & 3.248 & 1.656 & 1.370 & 1.645 \\
\hline $6^{a}$ & 9.182 & - & - & - & - & 42 & 184 & 2.329 & 2.944 & 1.672 & 2.011 \\
\hline $7^{\mathrm{a}}$ & 8.852 & - & - & - & - & - & 2 & 455 & 2.311 & 2.772 & 3.312 \\
\hline $8^{\mathrm{a}}$ & 7.851 & - & - & - & - & - & - & 3 & 438 & 2.392 & 5.018 \\
\hline Total & 70.572 & 281 & 2.921 & 6.579 & 6.731 & 7.199 & 7.597 & 8.475 & 8.899 & 9.137 & 12.753 \\
\hline
\end{tabular}

Fonte: SEE/RJ.

Com os dados indicados na Tabela 7 , relativos à população escolarizável na faixa de 7 a 14 anos, o quantitativo dos que cursam ou já concluíram o ensino fundamental, e dos que freqüentam a CA ou o $\mathrm{PE}$, pode-se construir um quadro demonstrativo, conforme é mostrado na Tabela 8, coluna Niterói. Nesta tabela, a linha indicando a matrícula no ensino fundamental provém da Tabela 4 , as matrículas na CA e no PE provêm das Tabelas 5 e 6, a linha referente ao ensino fundamental concluído é resultado de uma estimativa, e a população tem como fonte o Censo de 1996 do IBGE, de acordo com a Tabela 1.

Tabela 8 - Demonstrativo de excesso ou escassez de escolaridade na rede de ensino em três municípios do Rio de Janeiro - 1996

\begin{tabular}{|l|r|r|r|}
\hline \multicolumn{1}{|c|}{ Tipo } & Niterói & São Gonçalo & Itaboraí \\
\hline Matriculados no ensino fundamental & 70.572 & 122.487 & 31.202 \\
\hline (-) Alunos com menos de 7 anos & $(281)$ & $(292)$ & $(17)$ \\
\hline (-) Alunos com mais de 14 anos & $(12.753)$ & $(27.820)$ & $(7.666)$ \\
\hline Matriculados CA com mais de 6 anos & 4.024 & 7.556 & 3.662 \\
\hline Matriculados PE com mais de 6 anos & 270 & 207 & 150 \\
\hline Ensino fundamental concluído (estimativa) & 441 & 742 & 23 \\
\hline = Matriculados ou formados: 7-14 anos & 62.273 & 102.880 & 27.354 \\
\hline & & & 117.805 \\
\hline População: Censo Demográfico & 55.284 & $(3.534)$ & 25.516 \\
\hline (-) Ajuste meta de escolaridade (3\%) & $(1.658)$ & 114.271 & 24.751 \\
\hline = Demanda escolar & 53.626 & & \\
\hline
\end{tabular}

Fonte: IBGE. 
Os resultados referentes a Niterói mostram que, se $97 \%$ da população na faixa de 7 a 14 anos freqüentar uma escola, o valor 8.647 indicaria o total de alunos matriculados que não se justificam pelos dados demográficos.

Diante deste resultado surpreendente, foi levantada a hipótese de haver no sistema de ensino em Niterói a participação de alunos provenientes de municípios vizinhos, principalmente São Gonçalo e Itaboraí. Avaliação análoga para estes dois municípios está também inserida na Tabela 8, a partir das mesmas fontes de dados.

Os ajustes na Tabela 8 com respeito à meta de escolaridade exigem um esclarecimento suplementar. Tais ajustes foram fixados em 3\% para os três municípios. Tal valor pode não ser considerado desejável em longo prazo, mas, diante dos resultados do Censo Escolar realizado em 1977, pode ser considerado realista, com respeito a Niterói e extremamente otimista no caso de São Gonçalo e Itaboraí. O Censo de 1977, discutido numa das seções do artigo, apontou uma taxa de não-freqüência à escola de
5,78\% em Niterói, enquanto para São Gonçalo e Itaboraí estas taxas eram muito superiores, a saber, $12,17 \%$ e $22,14 \%$ respectivamente.

\section{Censo Escolar de 1977}

Em novembro de 1977, foi realizado um Censo Escolar da Região Metropolitana do Rio de Janeiro. Tal Censo Escolar foi patrocinado pelo Ministério da Educação e Cultura (MEC) e efetivado em moldes equivalentes ao Censo Demográfico Nacional, com visita a todas as residências da área e o preenchimento individual de um formulário pelos adolescentes. Vetter e Carvalho (1983) fazem uma avaliação crítica deste Censo, assim como um histórico dos censos escolares anteriores feitos no País.

A Tabela 9 transcreve, para os três municípios relevantes ao presente estudo, importante informação sobre escolaridade constante da folha 86 do relatório final do referido Censo.

Tabela 9 - Alunos de 7-14 anos na escola e fora da escola em três municípios do Rio de Janeiro

\begin{tabular}{|c|c|c|c|c|c|c|c|c|c|}
\hline \multirow{3}{*}{ Município } & \multirow{3}{*}{$\begin{array}{c}\text { Total } \\
\text { N }\end{array}$} & \multirow{2}{*}{\multicolumn{2}{|c|}{$\mathrm{Na}$ escola }} & \multicolumn{6}{|c|}{ Fora da escola } \\
\hline & & & & \multicolumn{2}{|c|}{ Total } & \multicolumn{2}{|c|}{ S/ escolaridade } & \multicolumn{2}{|c|}{ Desistentes } \\
\hline & & $\mathbf{N}$ & $\%$ & $\mathbf{N}$ & $\%$ & $\mathbf{N}$ & $\%$ & $\mathbf{N}$ & $\%$ \\
\hline Niterói & 57.076 & 53.779 & 94,22 & 3.297 & 5,78 & 1.965 & 3,44 & 1.332 & 2,34 \\
\hline São Gonçalo & 105.856 & 92.976 & 87,83 & 12.880 & 12,17 & 7.315 & 6,91 & 5.565 & 5,26 \\
\hline Itaboraí & 18.136 & 14.248 & 78,56 & 3.888 & 21,44 & 2.215 & 12,21 & 1.673 & 9,23 \\
\hline
\end{tabular}

Fonte: Censo Escolar da Região Metropolitana do Rio de Janeiro, 1977.

Os elementos da Tabela 8 são autocompreensíveis, cabendo esclarecer que os alunos sem escolaridade correspondem aos que ainda não se apresentaram à escola, ou seja, àqueles atrasados para a $\mathrm{CA}$ e, dependendo da idade, àqueles condenados a se tornarem futuros adultos analfabetos. Os desistentes são mais conhecidos como evadidos do sistema e correspondem àqueles que freqüentaram a escola, mas a deixaram prematuramente, antes de concluírem o ensino fundamental, ou antes de completarem 14 anos.

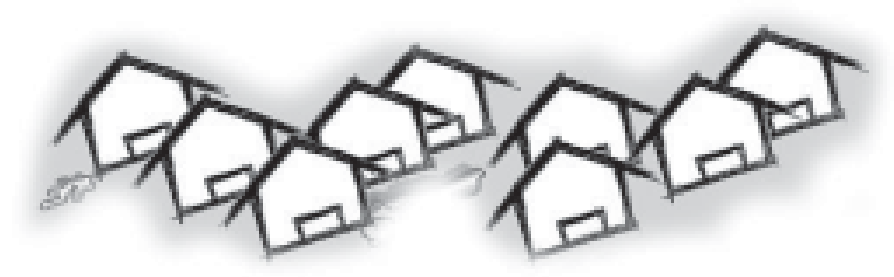




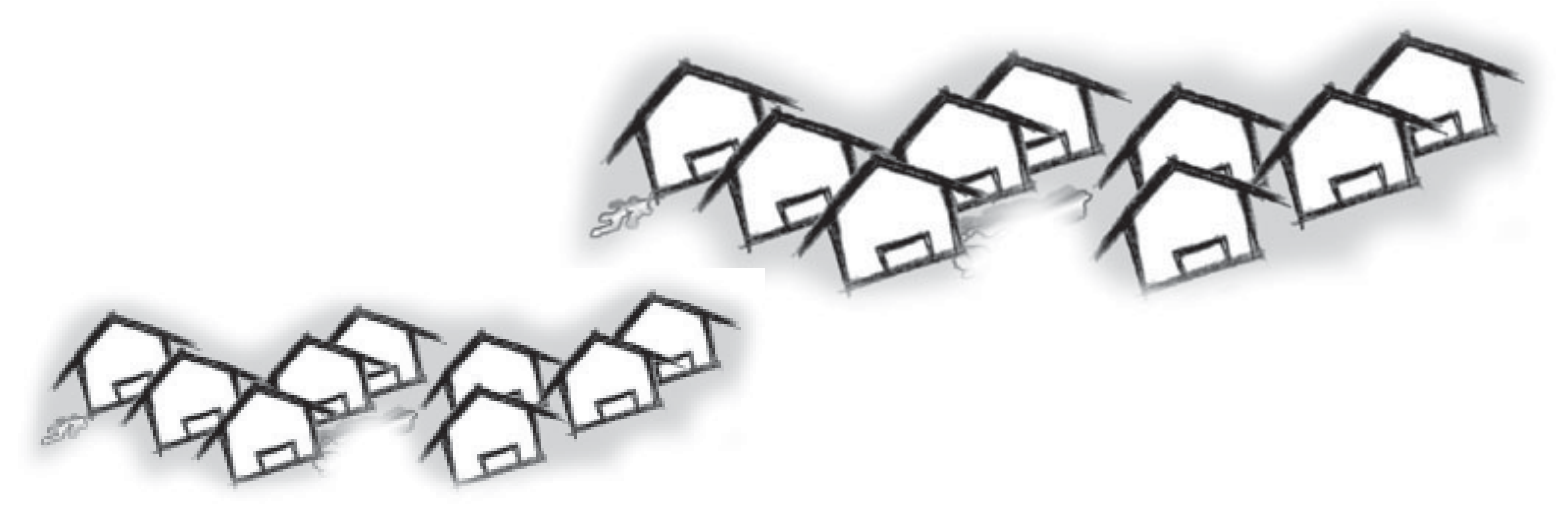

\section{Avaliação da localização das escolas}

O planejamento da localização de escolas é um problema complexo, especialmente nas grandes regiões metropolitanas do País, que, em passado recente, experimentaram um crescimento demográfico explosivo, promovido pela migração rural e pelas altas taxas de natalidade. Por outro lado, a escassez de recursos tanto econômicos como humanos e a ausência de políticas de priorização da educação prejudicaram o desenvolvimento do sistema público. As conseqüências mais evidentes nas regiões com menores recursos indicam que a evolução da rede pública não acompanhou o desenvolvimento urbano. Em particular, são evidentes tanto a insuficiente oferta global de vagas como a má distribuição espacial das escolas.

Por outro lado, a atual queda dramática das taxas de natalidade, conforme apontado pelo Censo de 1991, deu aos grandes centros urbanos um momento de relativa estabilidade demográfica, o que oferece uma oportunidade propícia para avaliar a distribuição espacial de suas escolas.

A metodologia de avaliação espacial, examinada a seguir, tem sido testada em diversos municípios da Região Metropolitana do Rio de Janeiro, como é mostrado em Pizzolato e Silva $(1993,1997)$ e Silva e Pizzolato (1996). Em termos bem simples, a metodologia supõe que o aluno busque a escola mais próxima de sua residência, e consiste em diversos passos, começando com a obtenção de mapas do município em estudo, nos quais estejam marcados os setores censitários, tais como definidos pelo IBGE e para os quais estejam disponíveis os dados correspondentes.
Como os setores censitários urbanos indicam pequenas áreas geográficas para o estudo de localização de escolas, tais setores representam uma discretização do espaço urbano, ou seja, pequenos aglomerados distribuídos por todo o município. Tais aglomerados permitem simplificar a distribuição espacial contínua, introduzindo pontos que concentram toda a população do setor. No caso de Niterói, o número de setores ultrapassa 500 , o que favorece uma boa descrição da distribuição espacial. Além de concentrar a população, estes pontos oferecem uma maneira aproximada de se definir e medir distâncias.

No passo seguinte, cada escola pública deve ser localizada no mapa, dentro de algum setor censitário, e dois tipos de estudos podem ser realizados. $O$ primeiro consiste em avaliar a localização atual das escolas e o segundo seria uma proposta de localização ideal. No caso de Niterói, por razões que serão analisadas adiante, somente a primeira parte do estudo foi feita, ou seja, a avaliação crítica da localização atual das escolas. Para este estudo, basta dispor do conjunto das escolas devidamente identificado no mapa, tornando-se trivial determinar, para cada setor, qual a escola mais próxima e, portanto, determinar a demanda por escola. A seguir, a comparação entre a demanda de cada escola e sua correspondente capacidade oferece uma estimativa do desequilíbrio existente entre oferta e demanda, que tanto pode ser um excesso ou escassez de vagas.

As Figuras 1, 2, e 3 ilustram o procedimento. A Figura 1 contém uma reprodução de um mapa, com a parte central do município de Niterói, incluindo as ruas centrais e adjacências. $O$ retângulo circunscrito mede, na base e na altura, cerca de $2.800 \mathrm{~m}$ e $3.100 \mathrm{~m}$, respectivamente. 


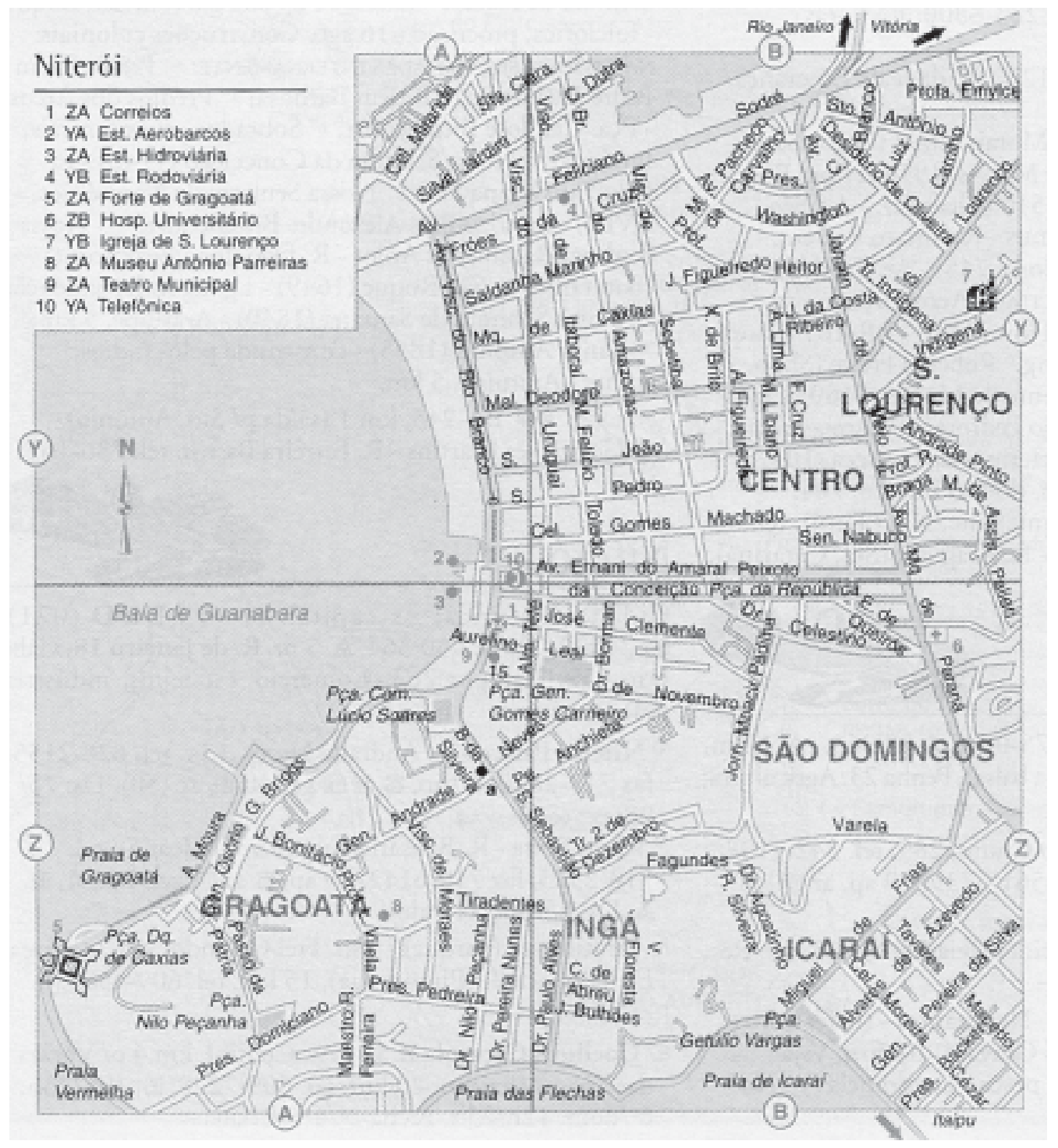

Figura 1 - Mapa da área central - Niterói

Fonte: Guia Quatro Rodas, 1997.

A Figura 2 é um mapa de trabalho com menor nitidez, que representa praticamente a mesma região mostrada na figura anterior, excluídas somente pequenas porções laterais do mapa. Na figura, estão exibidos os contornos dos setores censitários, tais quais definidos pelo IBGE para o Censo de 1980. Para o Censo posterior, de 1991, houve, nesta região, poucas alterações, resultantes de maior densidade populacional, novas construções habitacionais, novas favelas, etc. Tais modificações no mapa foram feitas à mão, a partir de indicações do IBGE. A Figura 3 incorpora tais alterações de forma a usar os resultados do Censo de 1991. A título de curiosidade, as grandes alterações de zoneamento censitário em Niterói foram observadas no seu segundo distrito, Itaipu, onde se nota um rápido desenvolvimento urbano. 


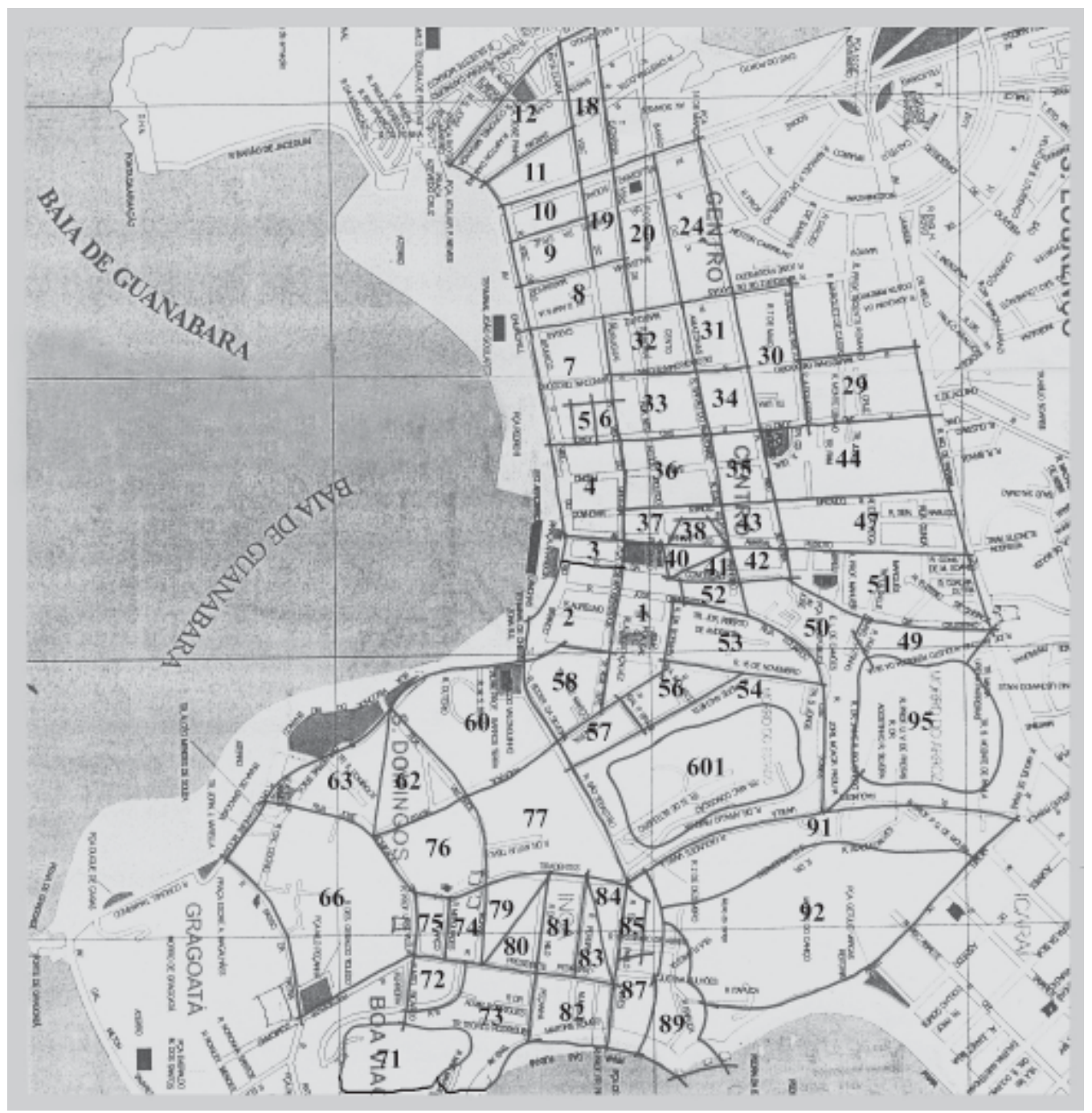

Figura 2 - Setores censitários da zona central - Niterói - Censo 1991

Fonte: Mapa da extinta Fundrem, 1977, atualizado para o Censo de 1991

A Figura 3 indica visualmente 0 zoneamento das escolas públicas no centro de Niterói, de acordo com o critério de proximidade. Para as sete escolas atualmente existentes, a figura foi suavemente explodida para melhor entendimento da metodologia. Olhando do norte para o sul da figura, há escolas nos seguintes setores: 10, 9, 33, 50, 62, 601 e 79, e as áreas destacadas indicam a região de abrangência de cada uma das escolas. Assim, a escola no setor 10, C. E. Raul Vidal, de acordo com esse critério, atrairia os escolares que moram no próprio setor 10 e nos setores vizinhos 11, 12, 18, 19, 20 e 24 . Como outro exemplo, no extremo sul da Figura 3, Bairro do Ingá, encontra-se no setor 79 o C. E. Aurelino Leal, atrairia, pelo mesmo critério de proximidade, os escolares que moram nos quatorze setores vizinhos. Trata-se de área intensamente povoada, com forte predominância da classe média.

Certamente, além da menor distância, há outros motivos para atrair um aluno a uma certa escola, especialmente diante da heterogeneidade das unidades da rede. Um dos mais significativos parece ser a existência do $2^{\circ}$ segmento do ensino fundamental e do ensino médio na própria escola, como forma de evitar a luta por vagas futuras. Em qualquer hipótese, a distância à escola desempenha um papel fundamental na escolha, conforme demonstrado por Pizzolato e Silva (1993), em estudo realizado em Nova Iguaçu. 


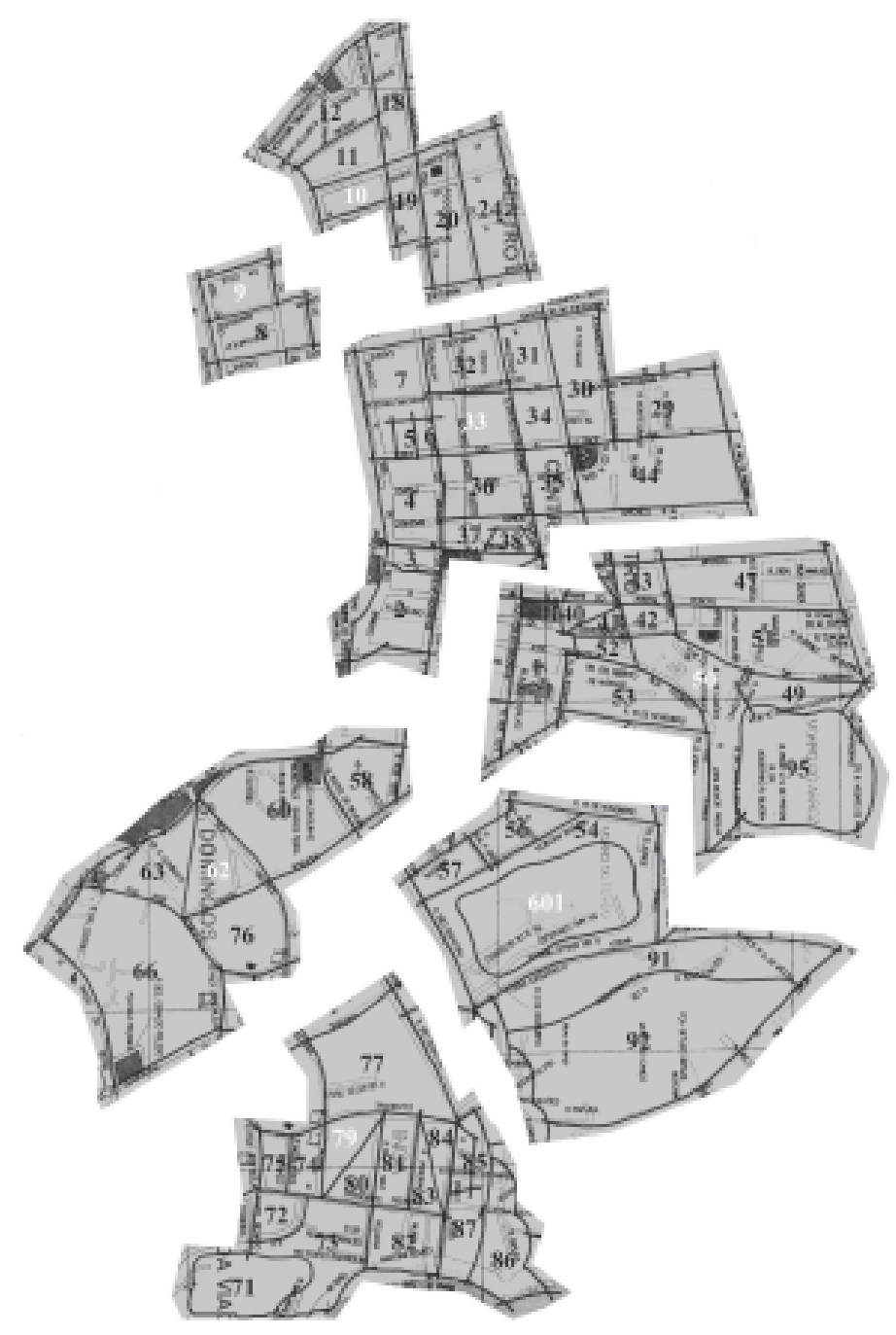

Figura 3 - Localização das sete escolas públicas na região central - Niterói - 1991

Fonte: Adaptação de Pizzolato, Silva e Mizubuti, a partir do mapa da Figura 2.

A avaliação da localização das sete escolas situadas na região central de Niterói pode ser melhor entendida com o auxílio da Tabela 10. Na primeira coluna, encontra-se o nome da escola; na segunda e terceira, estão a identificação do setor censitário e os setores atraídos a esta escola, de acordo com o critério de proximidade. A coluna seguinte indica a matrícula observada no ensino fundamental desta escola, no ano de 1991. A coluna posterior indica a população de 7 a 14 anos, estimada a partir dos dados do IBGE desagregados por setor, do Censo de 1991 e, finalmente, a última coluna indica o excesso ou escassez de vagas, de acordo com o critério de proximidade.
A título de exemplo, a primeira linha da Tabela 10 indica o C. E. Raul Vidal, localizado no setor censitário número 10, ao norte da região indicada nas figuras anteriores. Este colégio possui 1.490 alunos matriculados no ensino fundamental e, pelo critério de proximidade, atenderia aos moradores dos setores 11, 12, 18, 19, 20 e 24, os quais compreendem cerca de 535 alunos. Como conseqüência, haveria um excesso de 955 vagas. De acordo com visita ao local, essa ociosidade de vagas não é observada na prática, seja pela reputação de excelência desse colégio, pela sua singularidade em oferecer todos os níveis de ensino, seja pelo importante contingente, estimado em mais de $30 \%$ de alunos de outros municípios, favorecidos pela sua proximidade da rodoviária local.

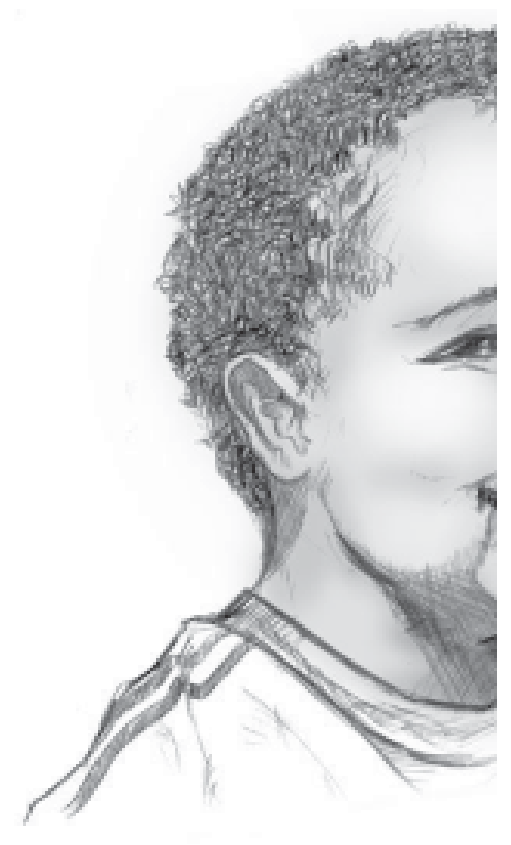


Tabela 10 - Avaliação da oferta e demanda em escolas públicas da região central de Niterói

\begin{tabular}{|c|c|c|c|c|c|}
\hline Nome da Escola & $\begin{array}{l}\text { Setor } \\
\text { IBGE }\end{array}$ & $\begin{array}{l}\text { Setores } \\
\text { vizinhos }\end{array}$ & $\begin{array}{l}\text { Matrícula no } \\
\text { ensino } \\
\text { fundamental }\end{array}$ & $\begin{array}{l}\text { População } \\
7-14 \text { anos }\end{array}$ & $\begin{array}{c}\text { Excesso } \\
\text { (ou escassez) }\end{array}$ \\
\hline C. E. Raul Vidal & 10 & $\begin{array}{l}11,12,18,19, \\
20,24\end{array}$ & 1.490 & 535 & 955 \\
\hline I. Conveniado Rotamirim & 9 & 8 & 38 & 145 & $(107)$ \\
\hline E. E. Pinto Lima & 33 & $2-7,29-38,44$ & 775 & 1.012 & $(237)$ \\
\hline $\begin{array}{l}\text { E. M. Alberto Francisco } \\
\text { Torres }\end{array}$ & 50 & $\begin{array}{l}1,40-43,47 \\
49,51,53,95\end{array}$ & 298 & 1.004 & $(706)$ \\
\hline E. E. Prof. Ismael Coutinho & 62 & $\begin{array}{l}58,60,63,66, \\
76\end{array}$ & 1.991 & 760 & 1.231 \\
\hline E. M. Airton Senna & 601 & $\begin{array}{l}54,56,57,91, \\
92\end{array}$ & 153 & 470 & $(317)$ \\
\hline C. E. Aurelino Leal & 79 & $\begin{array}{l}71-75,77,80- \\
85,87,89\end{array}$ & 787 & 1.721 & $(934)$ \\
\hline
\end{tabular}

Fonte: Pizzolato, Silva e Mizubuti, a partir de dados de população por setor censitário; IBGE 1996 e SEE/RJ.

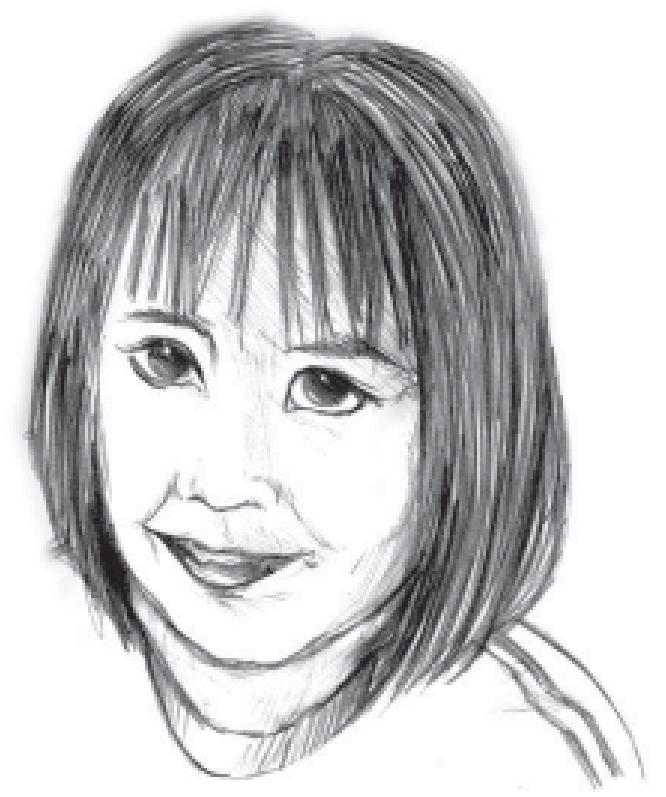

\section{Conclusões}

Diante do exposto, as conclusões mais significativas do presente estudo seriam as seguintes:

1) A metodologia de avaliação da capacidade da rede escolar, explicada numa das seções e ilustrada na Tabela 8, para três municípios, pode ser aplicada com facilidade a qualquer outro município, notando-se que as informações necessárias estão facilmente disponíveis no IBGE e no Inep/MEC, ou secretarias estaduais de ensino.

2) Estudos de localização de escolas podem ser feitos, conforme foi explicado, com recursos simples, desde que haja mapas disponíveis com os setores censitários marcados e dados demográficos do IBGE. Em diversas áreas metropolitanas, tais mapas podem eventualmente existir, mas a geocodificação de todas as regiões urbanas do País, em execução pelo IBGE, virá facilitar tais estudos.

3) No caso específico de Niterói, a presença significativa de alunos de outros municípios obedece a razões que exigem estudos suplementares, e que poderiam estar entre as seguintes: a) conveniências dos alunos ou de seus pais ou responsáveis; b) maior prestígio das escolas de Niterói e c) inexistência de vagas nos municípios de origem. Avaliação mais precisa da rede exige melhor conhecimento do fluxo de alunos migrantes, ou seja, para quais escolas eles se dirigem, de onde vêm, quais suas motivações, o modo de transporte, os custos em que eles incorrem, etc. A título de exemplo, o C. E. Raul Vidal, como já notado, está em área com excesso de vagas, mas, na prática, não há vagas 
ociosas. Pode tratar-se de diferenciação de qualidade, de melhor acessibilidade aos migrantes, etc. Situação análoga ocorre, surpreendentemente, em Itaboraí, onde em estudo recente, mas anterior, Silva (1995) mostrava haver escassez de vagas, além do Censo de 1977, que apontava um elevado contingente de jovens fora da escola (cf. Tabela 9).

4) Levando-se em conta a importante participação da rede particular de ensino no processo educacional de Niterói, especialmente em áreas predominantemente de classe média, como lcaraí, Ingá, São Francisco, Santa Rosa, Itaipu, etc., a atual localização de escolas poderia ser considerada bastante satisfatória. Por essa razão, mais o problema do fluxo de alunos migrantes, a parte do estudo direcionado à proposta de localização ideal não foi realizada. Naturalmente, se tais segmentos de classe média um dia optarem pelo sistema público, a revisão da rede deverá ser drástica, pois nas citadas regiões há forte escassez de vagas na rede pública. No caso do segundo distrito do município, Itaipu, sua rápida expansão populacional, da ordem de $10 \%$ ao ano, recomenda uma avaliação específica. Em futuro muito próximo, a construção de uma ou mais unidades pequenas deverá ser estritamente necessária. Mapas codificados e detalhes complementares podem ser encontrados em Silva (1995).
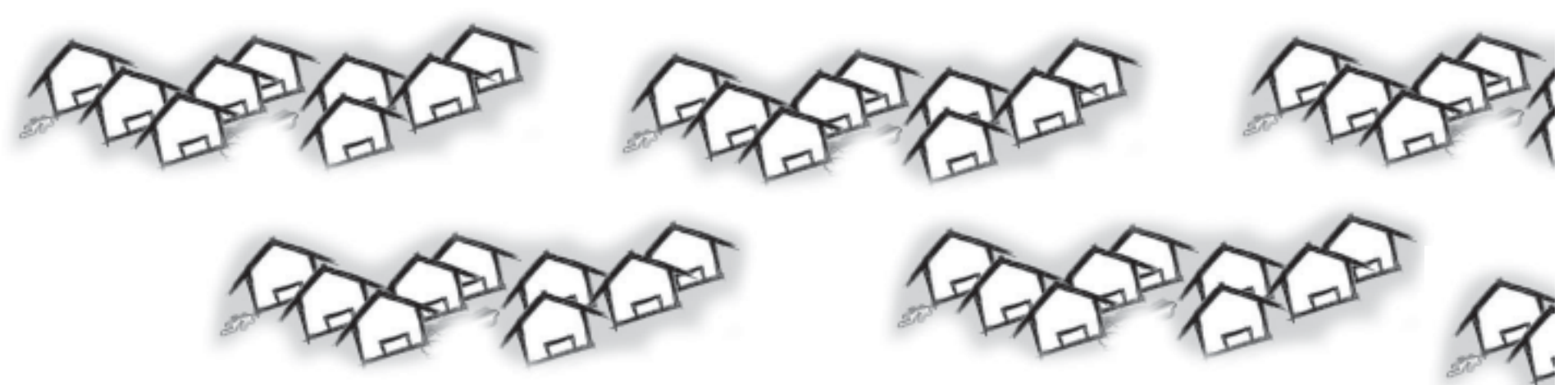

\section{Referências bibliográficas}

BRASIL. Ministério da Educação e do Desporto. Programa "Toda criança na escola". Brasília, 1997.

RIO DE JANEIRO. Secretaria Estadual de Educação e Cultura. $1^{\circ}$ Censo escolar da região metropolitana do Rio de Janeiro. Rio de Janeiro : Seec/RJ, 1977.

PIZZOLATO, Nelio D., SILVA, Hamilton B. Fraga da. Proposta metodológica de localização de escolas : estudo do caso de Nova Iguaçu. Pesquisa Operacional, Rio de Janeiro, v. 14, n. 2, p. 1-13, 1993.

. The location of public schools : evaluation of practical experiences. International Transactions in Operations Research, Oxford, v. 4, n. 1, p. 13-22, 1997.

RELATÓRIO executivo : convênio UFF/Prefeitura Municipal de Niterói. Projeto de localização de escolas. Niterói : Secretaria Extraordinária de Ciência e Tecnologia, 1995.

SILVA, Guilherme Gomes. Avaliação gerencial da localização de rede de ensino público de Niterói. Niterói, 1995. Dissertação (Mestrado em Engenharia Civil) - Universidade Federal Fluminense.

SILVA, Guilherme Gomes, PIZZOLATO, Nelio D. Avaliação gerencial da localização da rede de ensino público de Niterói. Ensaio, Rio de Janeiro, v. 11, p. 129-142, abr./ jun. 1996.

VETTER, David M., CARVALHO, José Carmelo B. Diagnóstico educacional dos municípios periféricos da região metropolitana do Rio de Janeiro. Revista Brasileira de Estudos Pedagógicos, Brasília, v. 64, n. 148, p. 165-190, set./dez. 1983. 
Recebido em 19 de janeiro de 1999.

Nelio D. Pizzolato, Ph.D em Business Administration pela Universidade de Carolina do Norte, EUA, é professor adjunto da Pontifícia Universidade Católica do Rio de Janeiro (PUC-Rio) e da Universidade Federal Fluminense (UFF).

Satie Mizubuti, doutora em Geografia Humana pela Universidade de São Paulo (USP), é professora adjunta do Departamento de Geografia da UFF.

Guilherme Gomes da Silva, mestre em Engenharia Civil pela UFF, é consultor de empresas de construção civil em Niterói (RJ).

\section{Abstract}

This work has two objectives, both illustrated with schooling data of the municipality of Niterói, State of Rio de Janeiro. Firstly, a methodology is proposed to evaluate the capacity of the public system to offer basic education to all the population in the 7-14 age range. Secondly, the location of the public schools is evaluated in order to identify areas with shortage or excess of school places. The surprising finding of the study was that the enrolled population is larger than the demographic one. The possible explanation would be the migration of students from neighboring municipalities. Regarding school location, the study has identified a few areas in which additional school places would be desirable but emphasized the fact that scarcity would be serious in the districts where the middle classes predominate if such class members would demand the public system rather than the private one.

(S)

Keywords: school location; capacity of the school system; basic education; school network. 